\title{
ANÁLISE DO FUNDO CONSTITUCIONAL DE FINANCIAMENTO DO NORTE COMO INSTRUMENTO PARA O DESENVOLVIMENTO REGIONAL
}

\section{ARTIGO ORIGINAL}

CARDOSO, Leandro dos Santos ${ }^{1}$

CARDOSO, Leandro dos Santos. Análise do Fundo Constitucional de Financiamento do Norte como instrumento para o Desenvolvimento Regional. Revista Científica Multidisciplinar Núcleo do Conhecimento. Ano 05, Ed. 09, Vol. 06, pp. 16-24. Setembro de 2020. ISSN: 2448-0959, Link de acesso: https://www.nucleodoconhecimento.com.br/administracao/fundoconstitucional

\section{RESUMO}

Os Fundos Constitucionais de Financiamento são instrumentos utilizados na busca pelo desenvolvimento das regiões brasileiras, historicamente afetadas pelo crescimento desigual do país. O FNO, especialmente, dedica-se ao crescimento e desenvolvimento econômico e social da região norte, por meio de financiamentos em infraestrutura e produção. Assim, com o objetivo de verificar a efetividade da política pública para o desenvolvimento da região norte buscou-se através da revisão bibliográfica dos principais artigos da área, analisar os principais resultados e conclusões, os quais apontaram que não é possível afirmar de forma clara a relação positiva entre o financiamento e o desenvolvimento regional, além disso, vários estudos demonstrarem que o fundo influenciou no aumento das desigualdades interregionais nos períodos analisados.

1 Pós-Graduado em Administração Pública pela Universidade Cândido Mendes, Graduado em Ciências Econômicas pela Universidade Federal de Goiás. 
Palavras-chave: FNO, Fundo Constitucional, Desenvolvimento Regional, Economia Regional.

\section{INTRODUÇÃO}

A desigualdade econômica e social entre as regiões brasileiras foi formado por um processo histórico que tem em suas raízes na colonização concentrada especialmente nas regiões litorâneas e percorrendo os principais ciclos econômicos, como o do ouro e café, chegando até a industrialização recente.

Essa questão foi evidenciada pós 1930, quando a industrialização brasileira não foi homogênea ou integrada, pelo contrário, a disparidade entre a região sudeste e as demais mostrou que essas regiões permaneciam presas a estruturas produtivas arcaicas e tradicionais acentuando ainda mais o subdesenvolvimento do país (COSTA, 2017).

Essa tendência que leva a concentração populacional e de renda pode ser explicada por um princípio conhecido por causalidade cumulativa ou circular, proposto por Myrdal (1957 apud THISSE, 2011), segundo o qual as desigualdades seguem em um efeito semelhante a uma "bola de neve", o que foi sintetizado por Krugman (1991 apud THISSE, 2011), como: "a produção manufatureira tenderá a se concentrar onde existir um grande mercado, mas o mercado será grande onde a produção manufatureira for concentrada".

Diante disso, as constituições federais que se seguiram abriram espaço para a problemática regional, entretanto, responsabilizavam a seca do Nordeste e a baixa ocupação do Norte como fatores do atraso econômico. Somente com a Constituição de 1988 o desenvolvimento regional foi tido como uma problemática de integração nacional centrando-se nas regiões que apresentavam progresso técnico e econômico atrasados em relação às economias dos estados do Sudeste e Sul do país.

Assim, para corrigir os desequilíbrios regionais ,no ano de 1989, por meio da Lei no 7.827, foi instituído o Plano Nacional de Desenvolvimento Regional - PNDR, o Fundo 
Constitucional de Financiamento do Nordeste - FNE, Fundo Constitucional de Financiamento do Centro-Oeste - FCO e o Fundo Constitucional de Financiamento do Norte - FNO como instrumentos de financiamento às atividades industriais e rurais a fim de reduzir a disparidade econômica da região Nordeste, Centro-Oeste e Norte rem relação à região Sudeste e Sul, sempre em consonância com as diretrizes dos Planos Nacionais de Desenvolvimento e articuladas por meio das instituições financeiras federais de caráter regional. O PNDR vem passando por atualizações periódicas, sendo a versão mais recente, promulgada, por meio de Decreto em maio de 2019.

Feito estas considerações, esta pesquisa se concentrará na descrição e análise do FNO, bem como apresentação dos principais resultados das pesquisas recentes sobre a efetividade do fundo no combate à desigualdade regional e suas principais consequências para o desenvolvimento da região norte, por meio de breve revisão bibliográfica.

\section{O FUNDO CONSTITUCIONAL DE FINANCIAMENTO DO NORTE}

Conforme Lei ำ 7.827, o FNO tem por objetivo contribuir para o desenvolvimento econômico e social da Região Norte tendo por diretrizes, dentre outras, a preservação ambiental, tratamento preferencial às atividades produtivas de pequenos e micro produtores rurais e pequenos e microempresários, preservação do meio ambiente e apoio a criação de novos centros e polos dinâmicos a fim de reduzir as desigualdades inter e intra-regionais (BRASIL, 1989).

Desta forma, a política consiste um fundo que fornece linhas de crédito e financiamento ao setor produtivo exclusivamente dos estados da região norte, a taxas juros menores que as praticadas no mercado privado e prazos maiores, que variam entre 12 e 20 anos (BASA, 2020).

Ainda segundo a Lei, o público alvo da política são os produtores, empresas, cooperativas, pessoas jurídicas ou físicas, que desenvolvam atividades produtivas nos setores agropecuário, mineral, industrial, agroindustrial, comerciais, turismo e serviços 
na região Norte e também empreendimentos de infraestrutura ligados ao setor público ou privado. Além disso, a partir de 2017, foram incluídos entre os beneficiários os estudantes matriculados em cursos superiores ou de capacitação profissional de instituições particulares, com potencial de contribuição para o desenvolvimento da região e em abril de 2020, foi criada uma linha de crédito específica para socorrer empresas que tiveram sua produção afetada pelas restrições impostas pela COVID19.

Nesse aspecto, o FNO divide-se ainda em diversos programas, conforme tabela no 1 , e dentro de seus programas há ainda a divisão e linhas financiáveis, que compreendem investimentos fixos e semifixos, custeio e capital de giro.

Quadro 1: Programas do FNO

\begin{tabular}{|c|c|c|}
\hline PROC & OBJETIVO & PÚBLICO ALVO \\
\hline $\begin{array}{l}\text { Programa Nacional de } \\
\text { Agricultura Familiar } \\
\text { (FNO-PRONAF) }\end{array}$ & $\begin{array}{l}\text { Apoio às atividades } \\
\text { agropecuárias voltados } \\
\text { à geração de emprego e } \\
\text { renda. }\end{array}$ & $\begin{array}{l}\text { Produtores rurais com } \\
\text { mão de obra } \\
\text { predominantemente } \\
\text { familiar }\end{array}$ \\
\hline 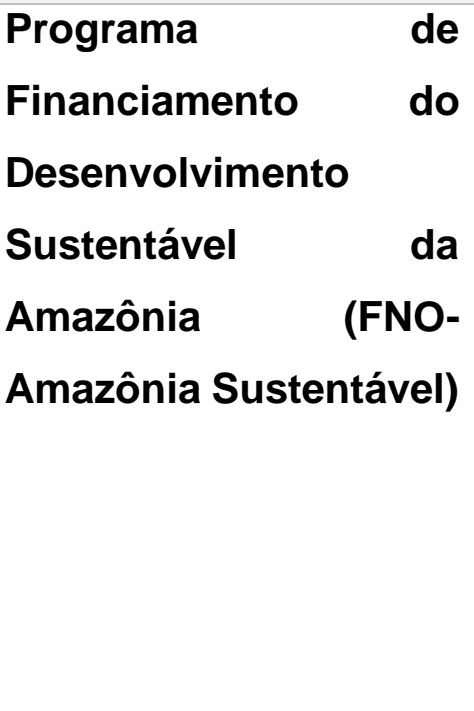 & $\begin{array}{l}\text { Apoio a } \\
\text { empreendimentos rurais } \\
\text { ou não rurais em bases } \\
\text { sustentáveis, por meio } \\
\text { de financiamentos } \\
\text { voltados } \\
\begin{array}{lr}\text { ampliação, } \\
\text { modernização } \\
\text { reformas }\end{array} \\
\text { empreendimentos. }\end{array}$ & $\begin{array}{l}\text { Produtores rurais (PJ ou } \\
\text { PF), associações e } \\
\text { cooperativas. }\end{array}$ \\
\hline $\begin{array}{l}\text { Programa de } \\
\text { Financiamento em } \\
\text { apoio à Agricultura de }\end{array}$ & $\begin{array}{l}\text { Apoio à técnicas } \\
\text { agroflorestais } \\
\text { sustentáveis, por meio }\end{array}$ & $\begin{array}{l}\text { Produtores rurais (PF e } \\
\text { PJ), associações, } \\
\text { cooperativas }\end{array}$ \\
\hline
\end{tabular}




\begin{tabular}{|c|c|c|}
\hline $\begin{array}{l}\text { Baixo Carbono (FNO- } \\
A B C)\end{array}$ & $\begin{array}{l}\text { investimento e custeio } \\
\text { de técnicas sustentáveis } \\
\text { ou sistemas de plantio }\end{array}$ & $\begin{array}{l}\text { populações tradicionais } \\
\text { da Amazônia não } \\
\text { atendidas } \\
\text { PRONAF. }\end{array}$ \\
\hline $\begin{array}{l}\text { Programa } \\
\text { Financiamento de } \\
\text { Micro e Pequenas } \\
\text { Empresas e aos } \\
\text { Microempreendedores } \\
\text { Individuais } \\
\text { MPEI) }\end{array}$ & $\begin{array}{l}\text { Apoiar } \\
\text { desenvolvimento } \\
\text { econômico e social por } \\
\text { meio de financiamentos } \\
\text { parar a ampliação, } \\
\text { modernização } \\
\text { inovação de práticas } \\
\text { produtivas } \\
\text { potencialização } \\
\text { atividades econômicas } \\
\text { em áreas urbanas. }\end{array}$ & $\begin{array}{l}\text { PJ e PF do setor } \\
\text { secundário e terciário; } \\
\text { Micro e Pequenas } \\
\text { empresas; MEl; Micro e } \\
\text { mini geradores de } \\
\text { energia. }\end{array}$ \\
\hline $\begin{array}{l}\text { Programa de } \\
\text { Financiamento } \\
\text { Estudantil (FNO-FIES) }\end{array}$ & $\begin{array}{l}\text { Reduzir desigualdades } \\
\text { regionais por meio da } \\
\text { promoção de mão de } \\
\text { obra qualificada }\end{array}$ & $\begin{array}{l}\text { Estudantes a nível de } \\
\text { ensino técnico, } \\
\text { graduação, mestrado e } \\
\text { doutorado. }\end{array}$ \\
\hline
\end{tabular}

Fonte: Elaboração própria a partir de informações do BASA (2020)

A Lei de criação dos fundos destinou 3\% da arrecadação do imposto de renda e proventos de qualquer natureza - IR e do imposto sobre produtos industrializados $\mathrm{IPI}$, dos quais $0,6 \%$ são destinados ao $\mathrm{FCO}, 1,8 \%$ ao $\mathrm{FNE}$ e os outros $0,6 \%$ ao $\mathrm{FNO}$. No ano de 2019, o fundo disponibilizou mais de 9 bilhões de reais atendendo a 450 municípios, por meio de 6.152 contratos. Para o ano de 2020, o fundo conta com mais de 7 bilhões de reais.

Ainda, segundo consta no Plano de Aplicação de Recursos do FNO, no ano de 2020, devem ser privilegiados o fornecimento de recursos aos municípios com renda considerada média, baixa e estagnada e os localizados em zona de fronteira, além de prever limites de financiamento por estado, a fim de evitar a concentração de recursos. 
A gestão do Fundo é um compartilhamento de atribuições entre Ministério do Desenvolvimento Regional, Superintendência do Desenvolvimento da Amazônia (SUDAM) e Banco da Amazônia (BASA), cabendo ao banco a análise dos projetos e liberação dos recursos, definindo normas, procedimentos e condições além de formalizar contratos e realizar a prestação de contas, e os demais órgãos compõem seu conselho deliberativo.

Nessa perspectiva, parece coerente do ponto de vista do federalismo ótimo que a gestão desse fundo seja de competência de órgãos do governo federal, uma vez que a política se destina ao desenvolvimento de uma região brasileira, de forma equitativa e sem privilegiar determinados estados ou municípios e especialmente porque uma das diretrizes do PNDR é o combate de desigualdades intra-regionais.

\section{IMPACTOS E RESULTADOS DA POLÍTICA}

Existem diversos pesquisas que buscaram investigar o impacto dos fundos constitucionais de financiamento sobre o desenvolvimento e a consequente redução das desigualdades regionais no Brasil, Oliveira e Domingos (2005) e Oliveira (2005), concluíram que no período de 1991 a 2000, os fundos do Centro-Oeste e do Norte foram pouco significativos na taxa de crescimento dos municípios destas regiões tendo por parâmetro a taxa de crescimento da renda per capita e PIB per capita estadual.

Por sua vez, Macedo e Matos (2008), ao analisar conjuntamente os fundos constitucionais do Norte, Nordeste e Centro-Oeste, entre os anos de 1989 a 2015 e subperíodos, concluíram que a política tem poder limitado no combate à desigualdade regional e apresenta tendência à concentração de renda em grandes municípios, capitais e regiões metropolitanas e até mesmo em grandes produtores rurais.

Ferreira e Mendes (2003), ao investigarem o período de 1990 a 1999 concluíram que o FNO contribuiu positivamente com o desenvolvimento do setor agrícola porém, foi insuficiente para reduzir a desigualdade no meio rural, apontando mais uma vez para 
o fenômeno da concentração de renda a favor de empresários e agricultores de maior porte.

Já Galeano e Feijó (2012), utilizando a análise de dados em painel, encontraram resultados positivos e significativos na relação entre o crédito do FNO e PIB per capita e produtividade no período de 2000 a 2008.

Resende (2017), ao analisar, no período de 2004 a 2010, o desempenho do FNO nos três principais setores abrangidos: rural, industrial e comércio/serviços, verificou a existência de uma relação positiva entre crescimento do PIB per capita e a oferta de fundos ao setores analisados. Entretanto, não há resultados estatisticamente significativos nas escalas microrregional e mesoregional. Resende ainda pondera que não foi possível mensurar a existência de efeito deslocamento, ou mesmo medir a existência de peso morto, que seria a verificação de quais os efeitos caso os investimentos fossem realizados por empresas privadas, sem subsídio governamental.

O trabalho de Silva et al (2009), propõe investigar a eficiência dos gastos com fundos constitucionais na geração de empregos da regiões abrangidas por cada fundo no período de 2000 a 2003, estabelecendo um contraste entre as empresas beneficiadas, e as que não receberam financiamento. A pesquisa não observou relação entre os investimentos do FNO na geração de empregos na região ou mesmo melhora de salários.

Já Macedo e Matos (2007) verificando a geração de empregos, estimaram que para cada $R \$ 9,8$ mil reais investidos na região Norte, gera-se 1 emprego, contra $R \$ 3,3$ e $\mathrm{R} \$ 16,5$ da região Nordeste e Centro-Oeste. O estudo apontou ainda que entre os anos de 2000 a 2005, juntas, as três regiões abrangidas pelos fundos apresentaram uma taxa de crescimento de $4,3 \%$, enquanto no restante do Brasil essa taxa foi de $4,9 \%$.

Esses autores questionaram ainda se os recursos dos fundos constitucionais foram diversificados setorial e espacialmente entre os municípios de cada região abrangida 
pelos fundos constitucionais, ou se, ao contrário, concentraram-se nos municípios que já detinham maior poder econômico, contribuindo assim, para o aumento das desigualdades intra-regionais. A conclusão do estudo foi que para o FNO, no período de 1989 a 2005, o financiamento de atividades rurais representou mais de $98 \%$ do recursos financiados e destes, a maior parte foi concentrada em médios e grandes produtores.

Quanto a distribuição espacial, Macedo e Matos (2007) concluíram que existe uma concentração maior da oferta de financiamento por meio dos fundos constitucionais em capitais, regiões metropolitanas e cidades com alto PIB, dado que estes municípios dispõem de melhor infraestrutura, maior desenvolvimento e acesso mais fácil à rede bancária e informações técnicas. Assim, ressaltam que deve haver no lado da oferta mecanismos que promovam a quebra dessa lógica de mercado, ofertando assim, mais crédito em municípios pequenos.

Em estudo mais recente, Sampaio (2017), também verificou que entre 1995 e 2012 há uma maior concentração dos financiamentos nas grandes cidades, entretanto, a partir do ano de 2012, mediante novas diretrizes do conselho deliberativo da SUDAM houve um maior adensamento de recursos em municípios com menos de 50 mil habitantes. Segundo o autor, esses novos números sugerem uma maior capilaridade das atividades do Banco da Amazônia e o atingimento dos objetivos propostos no PNDR.

Em contrapartida, segundo informações presentes no relatório de atividades, o Banco da Amazônia, estima que mediante o investimento de aproximadamente 7 bilhões que o fundo realizou, há um impacto de incrementar em 88 milhões o valor bruto da produção, aumentar em 45 milhões o PIB da região norte e ainda criar cerca de 1,2 milhão de novos empregos, gerando quase 9 milhões em salários e elevar a arrecadação em 13 milhões (BASA, 2020). 


\section{CONCLUSÕES}

Diante da análise dos diversos estudos realizados sobre o FNO percebe-se que em sua maioria, não foi possível comprovar a eficiência da política no atingimento da meta que é o desenvolvimento da região norte, entretanto, parece ser bem claro que, em certo grau, o fundo constitucional do norte não foi capaz de combater o aumento das desigualdades dentro da região Norte, onde microrregiões e setores mais desenvolvidos abocanham a maior parte dos recursos, fomentando ainda mais seu setor rural e industrial, concentrando renda, empregos e produtividade.

Isso parece ser a principal externalidade de consumo da política, que pode ser resultado de falhas sérias na sua implantação. Isso porque o PNDR prevê que áreas de fronteira, pequenos municípios e economias menores e estagnadas tenham maior atenção do fundo, o que aparentemente não vinha sendo, embora em anos mais recentes tenha se tornado uma prioridade, de fato.

A causa desses fatores parece estar associado à dinâmica do mercado, isso porque os fundos são concedidos por meio de demanda dos interessados, assim, é de se supor que atividades produtivas melhore estruturadas possuam mais recursos técnicos, financeiros e garantias que facilitem a obtenção do crédito. Além disso, a política prevê além de apoio financeiro o apoio técnico aos beneficiados, o que aparentemente não vem ocorrendo.

Essa falha no desenho da política que causa essa concentração de recursos pode impedir o efeito transbordamento positivo esperado pelo PNDR, criando, ao contrário, uma impedimento à pulverização do desenvolvimento, isso porque as cidades que concentram esses recursos tendem a atrair mão de obra mais qualificada, prejudicando as chances de desenvolvimento das regiões vizinhas.

Desta forma, restam inúmeros aspectos a serem analisados a fim de verificar, de fato, a efetividade da política, desde a infraestrutura da região norte, seu cenário político e ainda as dificuldades logísticas e até mesmo considerar efeitos diferentes do FNO em 
escala municipal e microrregional, e ainda a existência de outros impulsionadores de desenvolvimento presentes na região.

\section{REFERÊNCIAS}

ALMEIDA JÚNIOR, M.; RESENDE, G. M.; SILVA, A. M. Distribuição espacial dos fundos constitucionais de financiamento do Nordeste, Norte e Centro-Oeste. Revista de economia, v. 33, n. 2, p. 115-137, 2007.

BRASIL. Decreto ํ 9.810, de 30 de maio de 2019. Institui o Plano Nacional de Desenvolvimento Regional. Diário Oficial da União: edição extra, Brasília, DF, ano 131, 30 mai. 2019.

BRASIL. Lei n 7827, de 27 de setembro de 1989.Regulamenta o Art. 159, inciso I, alínea c, da Constituição Federal. Diário Oficial da União: seção 1, Brasília, DF, ano 101,28 set. 1989 .

COSTA, R. Política Regional na Amazônia: a II PNDR. Desenvolvimento Regional no Brasil: Políticas, estratégias e perspectivas. Instituto de Pesquisa Economia Aplicada, 2017.

Fundo Constitucional do Norte. Banco da Amazônia, 2020. Disponível em: https://www.bancoamazonia.com.br/index.php/sobre-o-banco/fno. Acesso em: 06 de julho de 2020.

Fundos Constitucionais de Financiamento do Norte e do Centro-Oeste na redução da desigualdade regional no Brasil. In: ENCONTRO NACIONAL DE ECONOMIA, 33, 2005, Natal, Rio Grande do Norte. Anais eletrônicos. Natal: ANPEC, 2005.

GALEANO, E. A. V.; FEIJÓ, C. Crédito e crescimento econômico: evidências a partir de um painel de dados regionais para a economia brasileira. Revista econômica do Nordeste, v. 43, p. 201-219, 2012. 
MACEDO, C. M.; MATTOS, E. N. O papel dos fundos constitucionais de financiamento no desenvolvimento regional brasileiro. Ensaios FEE, v. 29, n. 2,p. 355-384, 2008.

MACEDO, F.C. ; MATOS, E.N.; O papel dos Fundos Constitucionais de Financiamento no Desenvolvimento Regional Brasileiro. In: XII Encontro da Associação Nacional de Pós-Graduação e Pesquisa em Planejamento Urbano e Regional, 12, 2007, Belém, Pará. Anais Eletrônicos. Belém, 2007.

OLIVEIRA, H.C. Desigualdade Regional e os Fundos Constitucionais de Financiamento no Brasil. 2005. 108f. Dissertação (Mestrado em Economia) Faculdade de Ciências Econômicas da Universidade Federal de Minas Gerais, Belo Horizonte, 2005.

RESENDE, G.M. Avaliação dos Impactos Econômicos do Fundo Constitucional de Financiamento do Norte (FNO) entre 2004 e 2010. Avaliação de Políticas Públicas no Brasil: uma análise de seus impactos regionais. Instituto de Pesquisa Econômica Aplicada, Rio de Janeiro, 2014.

SAMPAIO. D.P. Diagnóstico do Fundo Constitucional de Financiamento do Norte. Avaliação de Políticas Públicas no Brasil: uma análise da política nacional de desenvolvimento regional (PNDR). Instituto de Pesquisa Econômica Aplicada, Rio de Janeiro, 2017.

SILVA, A.M.A; RESENDE,G.M.; SILVEIRA.R.M; Eficácia do Gasto Público: Uma Avaliação do FNE, FNO e FCO. Estatística Econômica, V.39, oํ 1, p. 89-125, janeiromarço, 2009, São Paulo.

THISSE, J.F. Política Regional na Amazônia: a II PNDR. Desenvolvimento Regional no Brasil: Políticas, estratégias e perspectivas. Instituto de Pesquisa Economia Aplicada, Rio de Janeiro, 2017.

Enviado: Agosto, 2020. 
Aprovado: Setembro, 2020. 